\title{
Оценка сравнительного потенциала увеличения торговли регионов Дальнего Востока со странами АТP
}

\author{
Дмитрий Изотов \\ Информация о статье \\ Поступила в редакичюю: \\ 04.09.2020 \\ Принята \\ к опубликованию: \\ 19.10.2020 \\ УдК $332+339$ \\ JEL R110, F140
}

Институт экономических исследований ДВО РАН, г. Хабаровск, Россия

\section{Ключевые слова:}

товаропоток, торговые барьеры, тарифная нагрузка, таможенная пошлина, институциональная нагрузка, гравитационная модель, панельные данные, регион, макрорегион, АТР, Дальний Восток

\section{Keywords:}

trade, trade barriers, tariff burden, customs duty, institutional burden, gravity model, panel data, region, macroregion, Asia-Pacific countries, Russian Far East

\begin{abstract}
Аннотация
В рамках современного подхода к оценке гравитационных зависимостей, на основе применения метода квазимаксимального правдоподобия Пуассона, определены сравнительные значения торговых барьеров, а также сравнительный потенциал расширения торговли регионов Дальнего Востока с ключевыми экономиками АзиатскоТихоокеанского региона (далее - АТР). При соотношении оченок, полученных в рамках традиционного и современного подходов к оченке гравитационных зависимостей, показаны схожие результаты и расхождения. Современный подход к оценке указал на заметный потенцииал для расширения торговли регионов Дальнего Востока со странами Северо-Восточной Азии, что подтверждает выводы о наращивании торговых взаимодействий между крупными и близлежащими экономиками в результате либерализации торговли.
\end{abstract}

Assessing the Comparative Potential for Increasing Trade of the Far East Regions With the APR Countries

Dmitry Izotov

\section{Abstract}

The objective of the paper is to assess comparative trade barriers between the regions of the Russian Far East and the countries of the Asia-Pacific region based on the modern approach to assessing gravity models, as well as to assess the potential for increasing mutual trade. The author has shown that the countries of the Asia-Pacific region are the largest trading partners for the Russian Far East (RFE), characterizing perceptible differences in the geographical and regional structure of the trade interactions. Since the customs duties on RFE exports are high, it is the main source of the tariff burden on the mutual trade. The findings indicate the following similar results between the traditional and modern approaches: the lowest comparative value of the trade barriers is typical for the trade between 
the RFE and the Republic of Korea; the trade between the RFE on the one hand and China and the Republic of Korea on the other has intensified; reducing the tariff barriers was not sufficient to boost the trade between the RFE and the Asia-Pacific countries; trade restrictions initiated by the Russian side resulted in a transition from the tariff barriers to the institutional ones; the groups of the RFE regions with similar characteristics of the comparative potential for expanding trade relations with the Asia-Pacific countries were identified. The evaluation shows some differences in outcomes between the two approaches. First, under the traditional approach the trade barriers were generally overestimated, so the estimates using the modern approach were more realistic, reflecting the possible changes in the price of foreign goods. Second, using the modern assessment approach, expanding the trade between the RFE regions and the close markets in the Northeast Asia (Korea, China and Japan) has a greater potential than with the remote countries (USA and South-Asian countries). These assessments support the early findings that trade interactions between the large and neighboring economies has a high potential as a result of trade liberalization.

\section{Введение}

Для России объективно возникла необходимость диверсификации внешней торговли в пользу стран и объединений, заинтересованных в поставках отечественной продукции и предлагающих товары, удовлетворяющие российский потребительский и инвестиционный спрос. Несмотря на то, что за последнее десятилетие Россия в целом увеличила товарооборот со странами АТР, российская сторона продолжает крайне неспешно подходить к расширению географии торговой либерализации, ограничиваясь главным образом некоторыми странами постсоветского пространства. Российская сторона, по всей видимости, должна активно осуществлять позиционирование на рынке стран АТР, прилагая усилия по созданию условий для взаимовыгодного экономического сотрудничества. В противном случае для России и ее территорий, географически расположенных в АТР, к которым относится Дальний Восток, могут создаться предпосылки для торгово-экономической изоляции в субглобальном регионе.

Развитие экономики Дальнего Востока России во многом определяется масштабами торгово-экономической деятельности. В силу объективных причин внешняя торговля Дальнего Востока ориентирована преимущественно на страны АТР, главным образом, расположенные в Северо-Восточной Азии (далее - CВА). Дальний Восток имеет возможности расширения внешнеторговых взаимодействий со странами АТР, что предполагает снижение различного рода барьеров, сдерживающих наращивание двусторонней торговли.

Одним из способов оценки торговых барьеров является гравитационное моделирование, при помощи которого возможно определить нагрузку на товаропоток между конкретными географическими объектами как в рамках товарной структуры взаимодействий [1], так и совокупного товарообмена на основе количественной оценки эффекта границ [2]. При помощи оценки в адвалорном эквиваленте нагрузки на товаропоток могут быть рассчитаны потенциальные значения торговли в случае нивелирования барьеров, сдерживающих торговые взаимодействия.

Оценки эффекта границ в подавляющем большинстве были получены в рамках традиционного подхода к гравитационным зависимостям на основе метода наименьших квадратов (далее - МНК) при логарифмировании зависимой переменной и исключении нулевых торговых потоков. В результате, 
как правило, получались сильно смещенные оценки. Принципиальные изменения в методологии расчетов гравитационных зависимостей, позволяющие получать несмещенные оценки и включать нулевые торговые потоки были внесены только за последнее десятилетие [3]. На основе сопоставления исследований, проведенных в рамках традиционного и современного подходов к оценке гравитационных зависимостей, можно заключить, что применение МНК ведет к переоценке эффекта границ, и зачастую к неверной интерпретации процессов торговых взаимодействий.

Для оценки торговых барьеров, сдерживающих взаимодействия российской экономики с различными зарубежными рынками, гравитационные модели использовались преимущественно в рамках традиционного подхода: для определения потенциала интеграции России с глобальной экономикой [4] и со странами ближнего зарубежья [5], а также для взаимодействия регионов России с зарубежными товарными рынками $[6,7]$. Для Дальнего Востока выделяются исследования, выполненные как в рамках традиционного подхода для определения эффекта границ с зарубежными странами и отечественным рынком $[8,9]$, так и современного - для определения факторов, объясняющих взаимодействие Дальнего Востока с некоторыми зарубежными странами [10].

В предыдущих исследованиях автора $[11,12]$ оценка торговых барьеров, а также определение потенциала торговых взаимодействий Дальнего Востока со странами АТР на основе оценки эффекта границ было осуществлено в рамках традиционного подхода. В результате: было обнаружено, что общий вектор интенсификации торговли Дальнего Востока наблюдался с Республикой Корея (далее - Корея) и Китаем; была осуществлена декомпозиция эффекта границ на институциональные и тарифные барьеры.

В рамках настоящего исследования будет задействован современный подход ${ }^{1}$ для оценки потенциала расширения торговых взаимодействий регионов Дальнего Востока со странами АТР, а также будет произведена декомпозиция эффекта границ, возникающих между дальневосточными регионами и странами субглобального региона. В результате, можно будет подтвердить или опровергнуть выводы, полученные в исследованиях на основе традиционного подхода к оценке. Также, оценка эффекта границ позволит определить общий вектор сравнительной интенсификации торговли Дальнего Востока в рамках географической структуры торговых взаимодействий макрорегиона со странами АТР, к которым в данном исследовании были отнесены: Китай, Корея, Япония, США и страны Юго-Восточной Азии (далее - ЮВА), включающие Тайвань и государства АCЕАН ${ }^{2}$. К Дальнему Востоку (ДФО) в исследовании отнесены девять субъектов Федерации по состоянию на 2018 г. ${ }^{3}$.

Целью исследования является оценка сравнительных значений торговых барьеров регионов Дальнего Востока со странами АТР, а также оценка сравнительного потенциала расширения торговли на основе современного

\footnotetext{
${ }^{1}$ Для оценки нелинейной гравитационной зависимости, позволяющей включать нулевые потоки, используется метод квазимаксимального правдоподобия Пуассона.

${ }^{2}$ Бруней, Вьетнам, Индонезия, Камбоджа, Лаос, Малайзия, Мьянма, Сингапур, Таиланд и Филиппины.

3 Амурская область, Еврейская автономная область (ЕАО), Камчатский край, Магаданская область, Приморский край, Республика Саха (РС) (Якутия), Сахалинская область, Хабаровский край и Чукотский автономный округ (ЧАО).
} 
подхода к оценке гравитационных зависимостей. Торговые барьеры, которые в данном исследовании синонимичны эффектам границ, включают в себя две группы ограничений: во-первых, тарифная нагрузка на двустороннюю торговлю, включающая в себя таможенные пошлины; во-вторых, институциональная нагрузка, определяемая другими ограничениями. В первом случае барьеры могут быть скорректированы в рамках текущей торговой политики, а для снижения институциональной нагрузки требуется всесторонняя либерализация торгово-экономических взаимосвязей, снижение различного рода рисков и т.д. Соотношение этих групп торговых барьеров позволяет определить сравнительный потенциал расширения двусторонней торговли с точки зрения реализации мер торгово-экономической политики.

\section{Методика оценки и данные}

На основе рекомендаций [13] для получения несмещенных оценок в гравитационных зависимостях предполагается, что в модель должны включаться: панельные данные для значительного улучшения общей эффективности оценки; фиксированные во времени эффекты для экспортеров и импортеров с целью контроля ненаблюдаемого многостороннего сопротивления и для любых других наблюдаемых и ненаблюдаемых изменяющихся характеристик; фиксированные эффекты для торгующих пар стран/регионов для учета неизменных во времени двусторонних торговых издержек [14]. Оценка гравитационной зависимости должна производиться методом квазимаксимального правдоподобия Пуассона. В этом случае решается проблема, связанная с наличием гетероскедастичности [3], и, соответственно, смещенности, а также появляется возможность включать «нулевые» торговые потоки в панельные данные.

Для решения проблемы эндогенности $[2,15]$ зависимая переменная корректируется на размер торгуемых между собой экономик $i$ и $j$. В итоге, для задач настоящего исследования зависимость оценивается в нелинейной форме методом квази-максимального правдоподобия Пуассона (КМПП):

$$
\frac{x_{i j}}{y_{i} y_{j}}=\exp \left[k+(1-\sigma) \rho \ln d_{i j}+(1-\sigma) \ln b_{i j}-(1-\sigma) \ln P_{i}-(1-\sigma) \ln P_{j}\right] .
$$

где: $x_{i j}$ - товаропоток из страны $i$ в страну $j ; y_{i}$ - размер экономики страны $i ; y_{j}$ - размер экономики страны $j ; P_{i}$ - цены в стране $i$, отражающие внешнее многостороннее сопротивление для страны-экспортера $i$; $P_{j}$ - цены в стране $j$, отражающие внутреннее многостороннее сопротивление для страны-импортера $j ; \sigma-$ постоянная эластичность замещения в потреблении товаров из страны $i$ в стране $j^{4} ; b_{i j}$ - ненаблюдаемая переменная, отражающая эффект границ между странами $i$ и $j, d_{i j}$ - физическое расстояние между $i$ и $j$. Выражение $\frac{x_{i j}}{y_{i} y_{j}}$ отражает интенсивность товаропотока между странами. Эффект границ в (1) определяется как $\hat{\beta}_{b}=(1-\sigma) \ln b_{i j} \Rightarrow b_{i j}-1=e^{\left(\frac{\hat{\beta}_{b}}{1-\sigma}\right)}-1$, а многостороннее сопротивление контролируется в фиксированных эффектах [16].

\footnotetext{
${ }^{4}$ Как правило, значение данного параметра, исходя из опыта других эмпирических исследований, задается равным пяти.
} 
Важно заметить, что дальнейшее использование тарифной нагрузки для декомпозиции эффекта границ не позволяет включать в панель товаропотоки с отечественным рынком. Поэтому, отечественный рынок не может быть использован в дальнейших расчетах и полученный эффект границ макрорегиона с остальными странами АТР будет являться, как и в прошлом исследовании [11], сравнительным ${ }^{5}$, отражая его превышение над эффектом границ Дальнего Востока с одной из стран субглобального региона. По этой причине, модель (2) представляется в следующем виде:

$$
\begin{aligned}
\frac{x_{i j t}}{y_{i t} y_{j t}}= & \exp \left[\beta_{0}+\beta_{1} K R_{i j}+\beta_{2} C N_{i j}+\beta_{3} J P_{i j}+\right. \\
& \left.\beta_{4} S A_{i j}+\beta_{5} U S A_{i j}+\beta_{6} \ln d_{i j}+\beta_{7} C O N T_{i j}+\lambda_{i t}+\lambda_{j t}\right]+\varepsilon_{i j t},
\end{aligned}
$$

где $x_{i j}$ - товаропоток из страны/региона $i$ в регион/страну $j ; y_{i}-$ ВВП страны/ВРП региона $i ; y_{j}-$ ВВП страны/ВРП региона $j ; t$ - временной промежуток. $d_{i j}-$ расстояние в километрах между $i$ и $j$. CONT - фиктивная переменная, отражающая наличие совместной сухопутной границы между регионом Дальнего Востока и страной АТР. Фиктивные переменные, отражающие значения эффекта границ, принимающие значения 1 или 0 в зависимости от направления товаропотока: $K R$ - торговля регионов Дальнего Востока с Кореей, $C N-$ с Китаем, $J P$ - с Японией, $S A$ - со странами ЮВА, USA - с США. Факторы, изменяющиеся в динамике и по странам/регионам, также контролировались включением фиксированных эффектов для регионов/стран экспортеров и импортеров с учетом времени $-\lambda$.

Эталонным показателем является двусторонняя торговля Дальнего Востока с одной из стран АТР, для этого последовательно тестировались пять альтернативных значений: товарооборот макрорегиона с Китаем, Кореей, Японией, США и странами ЮВА.

Массив показателей, характеризующих торговлю дальневосточных регионов с зарубежными странами, основывается на данных статистики Федеральной таможенной службы России по формам 1-ТС и 2-ТС (регион), которая была дополнена статистикой региональных подразделений ФСГС (Росстата), а также отраслевыми данными. Для оценки взаимодействия регионов Дальнего Востока с рынком АТР были отобраны только основные страны/группы стран, во избежание наличия отклонений в пользу эпизодичных, несущественных и нулевых торговых потоков.

Размер экономик (ВВП) стран АТР представлен значениями из базы данных МВФ, остальных российских регионов (ВРП) - данными ФСГС (Росстата). Во избежание искажений соответствия торговли размерам региональных экономик, в настоящем исследовании привязка экспортных/импортных товарных потоков к территориям их фактического производства/потребления не осуществлялась.

На основе информации о территориальной удаленности для морских и сухопутных перевозок в километрах оценены физические расстояния между регионами Дальнего Востока и странами АТР. Расстояния между странами

${ }^{5}$ В дальнейшем - «сравнительный эффект границ». 
АТР в дальневосточные регионы, не имеющие морских портов, определялись до порта Владивосток, далее, по железной дороге (для ЕАО и Амурской области) и по железной и автомобильной дорогам (РС Якутия). Китай в пространстве характеризуется различающимися входящими и исходящими торговыми потоками с дальневосточным рынком, поэтому расстояния во взаимодействиях оценивались как дифференцированные.

В итоге, модель (2) оценивалась на панельные данные с фиксированными эффектами по методу КМПП. Исходный массив данных, описывающих торговые взаимосвязи между объектами, был представлен двумя десятилетиями (1999-2018 гг.), включая 1800 наблюдений. Стоимостные показатели, использующиеся в исследовании, отражены в долларах США, и, согласно методическим рекомендациям [17], в текущих ценах.

\section{Результаты оценки}

Оценка сравнительного эффекта границ. Полученные в рамках модели (2) коэффициенты при регрессии показали, что торговые взаимодействия Дальнего Востока с Кореей характеризовались наименьшими из альтернативных значениями эффекта границ, поэтому, они были выбраны в качестве эталонных (табл.1).

Таблица 1

Значения коэффициентов регрессии модели (2) для Дальнего Востока со странами АТР

\begin{tabular}{|c|c|c|c|c|c|c|}
\hline \multirow{2}{*}{ Значения коэффициентов } & \multicolumn{2}{|c|}{ 1999-2018 } & \multicolumn{2}{|c|}{ 1999-2008 } & \multicolumn{2}{|c|}{ 2009-2018 } \\
\hline & I & II & I & II & I & II \\
\hline$C N$ (торговля между Дальним Востоком и Китаем) & $\begin{array}{c}-1,50 * * \\
(0,76)\end{array}$ & 45 & $\begin{array}{c}-1,62 * * * \\
(0,48)\end{array}$ & 50 & $\begin{array}{c}-1,06^{*} \\
(0,78)\end{array}$ & 30 \\
\hline$J P$ (торговля между Дальним Востоком и Японией) & $\begin{array}{c}-1,76^{* * * *} \\
(0,47) \\
\end{array}$ & 55 & $\begin{array}{c}-1,64 * * * \\
(0,47)\end{array}$ & 51 & $\begin{array}{c}-2,02^{* * * *} \\
(0,47)\end{array}$ & 66 \\
\hline $\begin{array}{l}\text { SA (торговля между Дальним Востоком и странами } \\
\text { ЮВА) }\end{array}$ & $\begin{array}{c}-1,78^{* * *} \\
(0,48)\end{array}$ & 56 & $\begin{array}{c}-1,77 * * * \\
(0,48)\end{array}$ & 56 & $\begin{array}{c}-1,78^{* * *} \\
(0,49)\end{array}$ & 57 \\
\hline USA (торговля между Дальним Востоком и США) & $\begin{array}{c}-2,05^{* * * *} \\
(0,48)\end{array}$ & 67 & $\begin{array}{c}-1,70^{* * *} \\
(0,49) \\
\end{array}$ & 53 & $\begin{array}{c}-2,25 * * * \\
(0,76)\end{array}$ & 76 \\
\hline CONT (совместная граница) & $\begin{array}{c}1,16^{* * *} \\
(0,13)\end{array}$ & - & $\begin{array}{c}1,65^{* * *} \\
(0,19)\end{array}$ & - & $\begin{array}{c}1,10^{* * *} \\
(0,09)\end{array}$ & - \\
\hline $\ln d$ (физическое расстояние) & $\begin{array}{c}-0,42 * * * \\
(0,07)\end{array}$ & - & $\begin{array}{c}-0,29 * * * \\
(0,10)\end{array}$ & - & $\begin{array}{c}-0,67 * * * \\
(0,11)\end{array}$ & - \\
\hline константа & $\begin{array}{c}-29,22^{* * * *} \\
(0,76)\end{array}$ & - & $\begin{array}{c}-29,69^{* * *} \\
(1,05)\end{array}$ & - & $\begin{array}{c}-27,17^{* * *} \\
(1,06)\end{array}$ & - \\
\hline количество наблюдений & 1800 & - & 900 & - & 900 & - \\
\hline Pseudo log-likelihood & $-6,71 \mathrm{E}-10$ & - & $-4,45 \mathrm{E}-10$ & - & $-2,02 \mathrm{E}-10$ & - \\
\hline Pseudo $R^{2}$ & 0,81 & - & 0,76 & - & 0,95 & - \\
\hline
\end{tabular}

Примечание: $*-\mathrm{p}<0,10 ; * *-\mathrm{p}<0,05 ; * * *-\mathrm{p}<0,01$. I - характеристики полученных оценок (2); II - адвалорный эквивалент сравнительного эффекта границ торговли Дальнего Востока со страной АТР, в \%. В скобках представлены робастные значения стандартных ошибок. Адвалорный эквивалент сравнительного эффекта границ оценен для $\sigma=5$

Источник: расчеты автора

Полученные оценки указали на негативное влияние расстояния на интенсивность торговли Дальнего Востока со странами АТР, что объясняет большую торговую ориентацию его экономики на географически близкие с ним страны - Корею, КНР и Японию - на которые суммарно приходилось более $80,0 \%$ товарооборота макрорегиона с зарубежным рынком, по сравне- 
нию с территориально удаленными США и странами ЮВА. В целом, наблюдалась также обратная связь между расстоянием и торговыми барьерами: чем больше расстояние между макрорегионом и торгуемой с ним страной, тем выше между ними значения эффекта границ. Для Дальнего Востока наличие совместной границы со странами АТР, а именно, с Китаем, способствовало увеличению торгового оборота между ними: в 2,2 раза больше по сравнению с другими регионами.

Следует отметить, что в динамике наблюдалось некоторое увеличение негативного влияния расстояния на товарооборот макрорегиона со странами ATP, что подтверждается расширением торговли Дальнего Востока только с близкими странами субглобальной экономики - странами СВА. С другой стороны, было замечено ослабление наличия совместной границы с зарубежной страной, поскольку в современных условиях наличие сухопутной границы с зарубежной страной не может оказывать эксклюзивно высокого воздействия на торговлю, по причине наличия других способов таких взаимодействий.

Сравнительный эффект границ в торговле макрорегиона с китайской экономикой имел тенденцию к ослаблению, с Японией и США, напротив, заметно вырос, а со странами ЮВА увеличился незначительно. С этой точки зрения, наблюдался рост сравнительной интенсивности торговых взаимодействий макрорегиона в пользу Китая и снижения - с другими странами АТР.

При сопоставлении оценок, полученных при помощи МНК и КМПП разброс значений сравнительного эффекта границ Дальнего Востока со странами АТР, в рамках современного подхода был не таким выраженным. Соотношение показало, что динамика значений эффекта границ, а также влияние расстояния и совместной границы в рамках двух походов имели одинаковые тенденции. Если отталкиваться от того, что значения эффекта границ, помимо фактора расстояния, отражают определенную надбавку к цене пересекающего границу товара, то полученные оценки в рамках современного подхода являются более реалистичными. Исключением являлась торговля Дальнего Востока с КНР, по которой значения сравнительного эффекта границ немного превосходили полученные значения в рамках традиционного подхода (рис.1).

В итоге завышения значений сравнительного эффекта границ в рамках традиционного подхода главным образом касались торговли макрорегиона с территориально удаленными экономиками: США и стран ЮВА. С этой точки зрения, подтверждается то обстоятельство, что в рамках современного подхода к оценке зависимость между интенсивностью торговли и расстоянием является нелинейной, существенно корректируя значения эффекта границ, особенно для значительно удаленных друг от друга экономических объектов.

\footnotetext{
${ }^{6}$ Для периода 2002-2017 гг. в рамках МНК были получены следующие значения сравнительного эффекта границ для Дальнего Востока: с КНР - 30\%, с Японией - 60\%, со странами ЮВА - $120 \%$, с США - 207\%. Подробно: [11].
} 


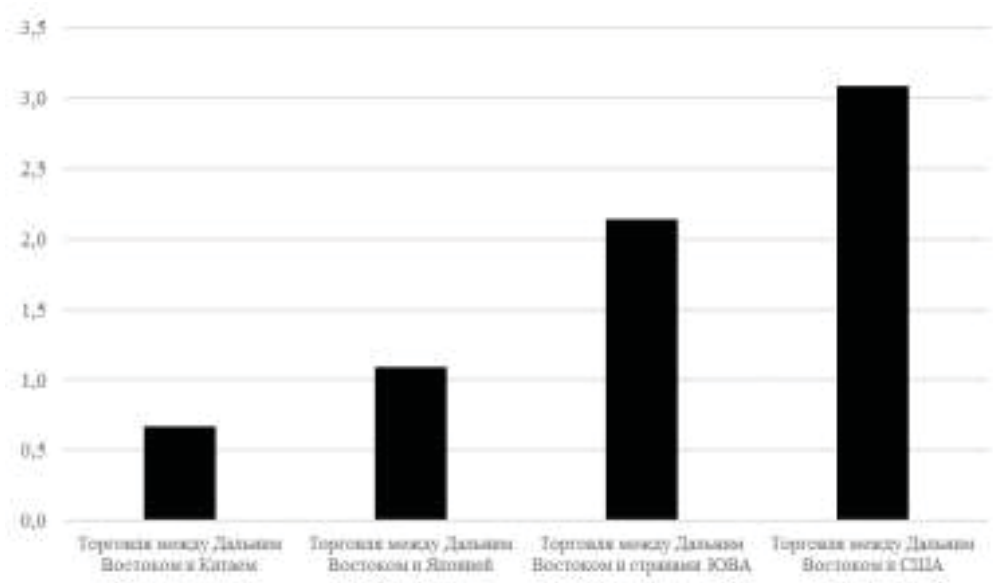

Puc.1. Соотношение значений сравнительного эффекта границ, полученных на основе оценки МНК и КМПП

Примечание: значения эффекта границ, полученные на основе оценки методом КМПП = 1 Источник: расчеты автора на основе сопоставления значений в табл.1 и полученных оценок в [11]

Декомпозииия сравнительного эффекта грании Дальнего Востока со странами ATP. В соответствии с анализом динамики таможенных пошлин, было определено, что, несмотря на осуществление формальной либерализации внешнеэкономической деятельности, экспортные и импортные пошлины, взимаемые на российской стороне, являлись основным источником тарифной нагрузки на товарооборот Дальнего Востока со странами АТР (рис.2).

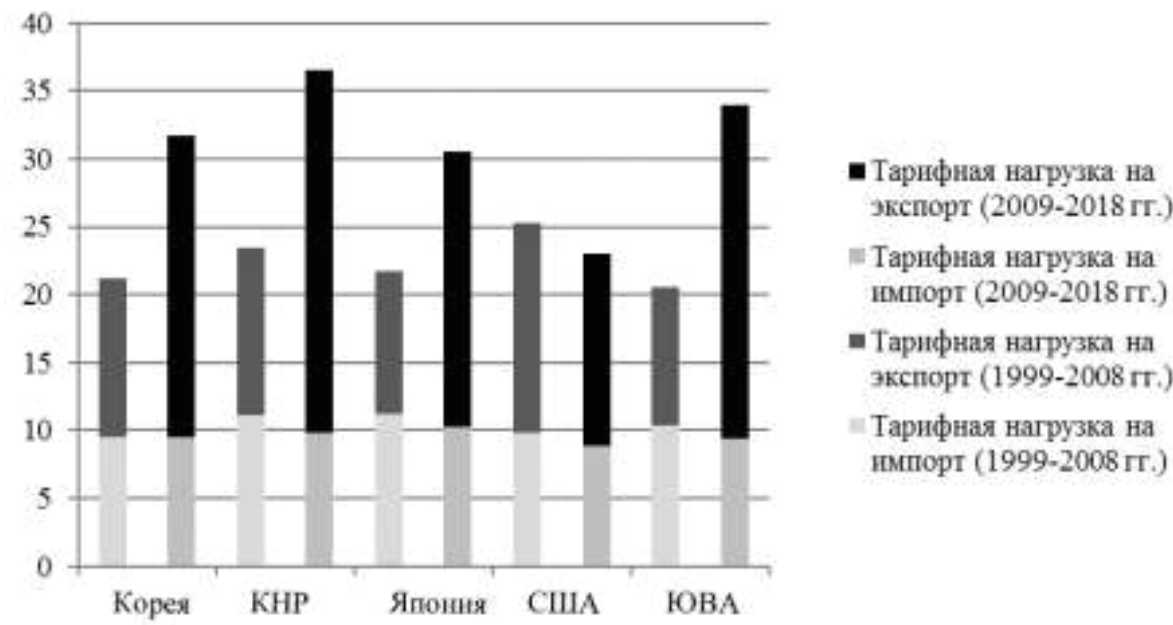

Puc.2. Средневзвешенные ставки таможенных пошлин (тарифная нагрузка) в торговых взаимодействиях Дальнего Востока со странами АТР, \%

Примечание: приведены абсолютные значения средневзвешенных ставок таможенных пошлин в торговле макрорегиона со странами АТР

Источник: расчеты автора

Анализ динамики взимаемых на российской стороне импортных пошлин без учета нетарифных ограничений внешней торговли, указал в целом на их некоторое снижение, что является не точным, поскольку даже если 
объемы импорта определенных товарных групп снижались или прекращались вовсе, то согласно значениям средневзвешенной пошлины общая тарифная нагрузка на импорт также сокращалась. Однако, происходило перемещение тарифной нагрузки в институциональную.

Поскольку эффект границ между Дальним Востоком и странами АТР является сравнительным, тарифная нагрузка также была приведена к базовой величине - торговле макрорегиона с Кореей в терминах относительного прироста ( $\left(\frac{\text { Tariff }_{j}}{\text { Tariff }_{K R}}\right)^{\frac{1}{(1-\sigma)}}-1$, где Tariff - тарифная нагрузка, KR - Корея, $\mathrm{j}$ - остальные страны АТР, $\sigma=5$ ) - для последующей оценки сравнительной институциональной нагрузки в адвалорном эквиваленте. В отличие от предыдущих [11, 12], в настоящем исследовании транспортные тарифы из числа компонентов торговых барьеров были исключены по причине того, что данные издержки были учтены в гравитационной зависимости. Декомпозиционная оценка показала, что вклад сравнительной институциональной нагрузки в эффект границ был существенно больше, чем сравнительной тарифной нагрузки для торговли макрорегиона со всеми рассматриваемыми странами АТР (табл.2).

Таблица 2

Декомпозиция сравнительного эффекта границ в торговых взаимодействиях Дальнего Востока со странами АТР, \%

\begin{tabular}{|l|c|c|c|c|c|c|c|c|c|}
\hline \multirow{2}{*}{$\begin{array}{c}\text { Торговля Дальнего } \\
\text { Востока со страной } \\
\text { АТP }\end{array}$} & \multicolumn{3}{|c|}{$\mathbf{1 9 9 9 - 2 0 1 8}$} & \multicolumn{3}{c|}{ 1999-2008 } & \multicolumn{3}{c|}{ 2009-2018 } \\
\cline { 2 - 11 } & I & II & III & I & II & III & I & II & III \\
\hline КНР & 45,0 & 0,00 & 45,0 & 49,9 & $-0,02$ & 50,0 & 30,3 & $-0,03$ & 30,4 \\
\hline Япония & 55,2 & 0,02 & 55,2 & 50,7 & $-0,03$ & 50,7 & 65,8 & 0,03 & 65,8 \\
\hline Страны ЮВА & 56,3 & 0,09 & 56,2 & 55,7 & 0,00 & 55,7 & 57,0 & 0,04 & 57,0 \\
\hline США & 66,8 & 0,02 & 66,8 & 53,0 & $-0,01$ & 53,0 & 75,6 & $-0,01$ & 75,6 \\
\hline
\end{tabular}

Примечание: I - сравнительный эффект границ в адвалорном эквиваленте; II - сравнительная тарифная нагрузка; III - сравнительная институциональная нагрузка. Отрицательный знак перед показателем сравнительной тарифной нагрузки указывает на меньшие его значения по отношению к средневзвешенной таможенной пошлине в торговле макрорегиона с Кореей

Источник: расчеты автора

Полученные оценки подтвердили выводы о недостаточности выравнивания тарифной нагрузки на товаропотоки из стран АТР между собой для снижения подавления интенсивности двусторонней торговли Дальнего Востока с близлежащим зарубежьем. Анализ также указал на то, что за последнее десятилетие, путем введения различного рода ограничений с российской стороны, наблюдалось смещение барьеров из тарифной в институциональную нагрузку на товарооборот.

Общий вектор интенсификации торговли Дальнего Востока в рамках географической структуры товарооборота со странами АТР, помимо Кореи, как отправной точки для получения сравнительной оценки, наблюдался во взаимодействии макрорегиона с китайской экономикой. Также как и при традиционном подходе, было зафиксировано снижение интенсивности торговли 
макрорегиона с территориально близким японским рынком за счет увеличения сравнительной институциональной нагрузки.

За рассматриваемый период сравнительная институциональная нагрузка на торговлю Дальнего Востока с Китаем снизилась, а с Японией и США увеличилась. Со странами ЮВА сравнительная институциональная нагрузка практически не изменилась.

Оценки торговых барьеров для макрорегиона показательны, но довольно агрегированы. К Дальнему Востоку относятся разные по своему масштабу региональные экономики, которые в ряде случаев значительно удалены друг от друга в пространстве, а также в различной степени связаны торговыми взаимодействиями с зарубежными рынками, в том числе со странами АТР.

В ходе оценки были получены статистически значимые коэффициенты панельной регрессии для каждого региона Дальнего Востока (2). В результате, были обнаружены определенные региональные различия в значениях сравнительного эффекта границ в адвалорном эквиваленте. Для лаконичности изложения количественные оценки эффекта границ для каждого региона Дальнего Востока не приводятся, но при этом будут показаны результаты его декомпозиции.

Декомпозиционная оценка эффекта границ показала, что за 1999-2018 гг., по сравнению с Кореей, более половины дальневосточных регионов преимущественно характеризовались большей институциональной нагрузкой с китайским рынком (табл.3).

Таблииа 3

Декомпозиция сравнительного эффекта границ

в торговле регионов Дальнего Востока со странами АТР (1999-2018 г2.), \%

\begin{tabular}{|l|c|c|c|c|c|c|c|c|}
\hline \multirow{2}{*}{\multicolumn{1}{c|}{ Регион }} & \multicolumn{2}{c|}{ КНР } & \multicolumn{2}{c|}{ Япония } & \multicolumn{2}{c|}{ США } & \multicolumn{2}{c|}{ Страны ЮВА } \\
\cline { 2 - 10 } & 1 & 2 & 1 & 2 & 1 & 2 & 1 & 2 \\
\hline РС (Якутия) & $-21,9$ & $-0,2$ & 15,6 & 0,2 & 51,0 & 0,0 & 47,1 & 0,2 \\
\hline Камчатский край & 91,4 & 0,1 & 96,3 & 0,2 & 127,9 & 0,2 & 127,6 & 0,1 \\
\hline Приморский край & 18,6 & 0,0 & 53,9 & 0,0 & 92,7 & $-0,1$ & 46,5 & 0,0 \\
\hline Хабаровский край & $-23,1$ & 0,0 & 40,5 & 0,0 & 68,2 & 0,1 & 12,2 & 0,4 \\
\hline Амурская область & $-48,5$ & $-0,1$ & 21,0 & 0,0 & 63,8 & 0,0 & 20,5 & 0,0 \\
\hline Магаданская область & 101,3 & 0,0 & 58,2 & 0,3 & 93,6 & 0,0 & 114,1 & $-0,1$ \\
\hline Сахалинская область & 97,3 & 0,0 & 55,0 & 0,0 & 119,2 & 0,2 & 46,5 & 0,2 \\
\hline ЕАО & $-11,0$ & 0,0 & 102,7 & 1,1 & 91,5 & 0,1 & 65,8 & 0,0 \\
\hline ЧАО & 30,8 & 0,2 & 67,9 & 0,1 & 45,8 & 0,0 & 87,9 & 0,1 \\
\hline
\end{tabular}

Примечание: 1 - сравнительная институциональная нагрузка; 2 - сравнительная тарифная нагрузка. Отрицательные знаки перед показателями сравнительной институциональной и тарифной нагрузками указывают на меньшие их значения по отношению к торговле макрорегиона с Кореей

Источник: расчеты автора

Для большинства регионов Дальнего Востока сравнительная институциональная нагрузка с КНР снижалась, что указывает на постепенную их ориентацию на торговлю с Китаем. По причине территориальной близости меньшей сравнительной институциональной нагрузкой с КНР в 1999-2018 гг. характеризовались: РС (Якутия), Амурская область, ЕАО и Хабаровский край. Данное обстоятельство означает, что сравнительный потенциал расширения 
торговли данных регионов с одной стороны, может быть связан в большей меpe c сокращением тарифной нагрузки с Китаем, чем с поиском путей для сокращения сравнительной институциональной нагрузки; с другой - любые другие альтернативы кроме китайского рынка могут быть менее актуальными.

В среднем за 1999-2018 гг. высокие значения сравнительной институциональной нагрузки в торговле с КНР наблюдались для Камчатского края, Магаданской и Сахалинской областей. Магаданская область характеризовалась самой малой долей в торговых взаимодействиях регионов Дальнего Востока с Китаем - менее $1,0 \%$. Возможно, в данном случае речь идет о наличии барьеров для входа китайских фирм в традиционную отрасль Магаданской области - добычу драгоценных металлов, что может сдерживать расширение торговли региона с Китаем. В свою очередь, Камчатской край и Сахалинская область во внешней торговле были ориентированы больше на корейский, чем на китайский рынок по причине специфичности географического положения и реализуемой на внешнем рынке продукции.

Торговые взаимодействия дальневосточных регионов с другим крупным рынком - японским - за некоторым исключением, были менее интенсивны по сравнению с Кореей и, отчасти, с КНР. За исключением РС (Якутия) сравнительный эффект границ в торговле с Японией для всех остальных дальневосточных регионов характеризовался высокими значениями. Как показали расчеты, именно сравнительная институциональная нагрузка для торговли с Японией вносила основной вклад в сравнительный эффект границ всех дальневосточных регионов и была заметно выше, чем с Республикой Корея.

Самыми высокими значениями сравнительной институциональной нагрузки я Японией характеризовалась ЕАО, а также Камчатский край (при этом ниже, чем с КНР). Действительно, из ЕАО в малом объеме и крайне эпизодически поставляются в Японию товары собственного производства. Также, в ЕАО поставляются японские товары, которые могут не учитываться таможенными органами, поскольку данная продукция поступает из других регионов Дальнего Востока - Приморского и Хабаровского краев. Можно заметить, что для Камчатского края импортный поток товаров и услуг, связанный с приобретением и ремонтом судов по добыче морских ресурсов не отражается в российской статистике, по причине регистрации данных морских судов в других странах, что могло повлиять на высокие значения барьеров.

По сравнению со странами СВА, сравнительный эффект границ с США практически для всех регионов Дальнего Востока характеризовался высокими значениями. Самые низкие значения сравнительной институциональной нагрузки наблюдались для территориально близкого к американской экономике ЧАО, а также для РС (Якутия). Для большинства регионов сравнительная институциональная нагрузка с США имела тенденцию к увеличению, в том числе и для ЧАО. Во внешней торговле большинства регионов Дальнего Востока долгое время заметную долю формировал импорт американской сельскохозяйственной продукции. Однако, после введения Россией запрета на поставку на отечественный рынок из США данного вида товаров, торговля с американским рынком сократилась, что отразилось в росте значений эффекта границ.

Другим территориально удаленным рынком для регионов Дальнего Востока являются страны ЮВА. Специфичные торговые взаимодействия 
дальневосточных регионов с данными странами влияли на рост значений эффекта границ, основу которого формировала институциональная нагрузка. Высокими значениями сравнительной институциональной нагрузки на торговлю со странами ЮВА характеризовались Магаданская область и Камчатский край. Из всех дальневосточных регионов низкой сравнительной институциональной нагрузкой на торговлю со странами ЮВА характеризовался только тот регион, который имел относительно устойчивый товарообмен с данной группой стран - Хабаровский край.

Возможное изменение товарооборота со странами АТР для дальневосточных регионов в случае выравнивания сравнительной институциональной нагрузки может существенно различаться (табл.4).

Таблицча 4

Сравнительный потенциал расиирения торговли регионов Дальнего Востока

\begin{tabular}{|c|c|c|c|c|c|c|c|c|c|c|}
\hline \multirow{2}{*}{ Регион } & \multicolumn{2}{|c|}{ Корея } & \multicolumn{2}{|c|}{ КНР } & \multicolumn{2}{|c|}{ Япония } & \multicolumn{2}{|c|}{ США } & \multicolumn{2}{|c|}{$\begin{array}{c}\text { Страна } \\
\text { ЮВА }\end{array}$} \\
\hline & 1 & 2 & 1 & 2 & 1 & 2 & 1 & 2 & 1 & 2 \\
\hline Дальний Восток & 1,0 & 14 & 1,2 & 228 & 1,5 & 420 & 1,9 & 102,9 & 1,4 & 48 \\
\hline РС (Якутия) & 1,2 & 12 & 1,0 & 0 & 1,2 & 22 & 1,5 & 53 & 1,5 & 8 \\
\hline Камчатский край & 1,0 & 0 & 1,9 & 408 & 2,0 & 309 & 2,3 & 140 & 2,3 & 55 \\
\hline Приморский край & 1,0 & 0 & 1,2 & 249 & 1,5 & 250 & 1,9 & 75 & 1,5 & 60 \\
\hline Хабаровский край & 1,2 & 55 & 1,0 & 0 & 1,4 & 77 & 1,7 & 34 & 1,1 & 17 \\
\hline Амурская область & 1,5 & 4 & 1,0 & 0 & 1,2 & 3 & 1,2 & 1 & 1,2 & 0 \\
\hline Магаданская область & 1,0 & 0 & 2,0 & 132 & 1,6 & 204 & 1,9 & 221 & 2,1 & 16 \\
\hline Сахалинская область & 1,0 & 0 & 2,0 & 1553 & 1,6 & 3743 & 2,2 & 617 & 1,5 & 265 \\
\hline EAO & 1,1 & 2 & 1,0 & 0 & 2,0 & 12 & 1,9 & 2 & 1,7 & 1 \\
\hline ЧАО & 1,0 & 0 & 1,3 & 262 & 1,7 & 68 & 1,5 & 238 & 1,9 & 21 \\
\hline
\end{tabular}

Примечание: 1 - отношение перспективных к текущим значениям внешнеторгового оборота (текущие значения

$=1$ ); 2 - разница между перспективными и текущими значениями товарооборота (на душу населения, долл.)

Источник: расчеты автора

При выравнивании сравнительной институциональной нагрузки в целом для Дальнего Востока в наибольшей степени может пропорционально увеличиться товарооборот с американской экономикой (в 1,9 раз).

Наибольшими значениями среднедушевого прироста торговли со странами АТР при снижении сравнительной институциональной нагрузки для торговли с Кореей характеризовался Хабаровский край, с остальными странами АТР - Сахалинская область. В целом, в большем выигрыше от снижения сравнительной институциональной нагрузки могут оказаться дальневосточные регионы с малой численностью населения и большим потоком экспорта с низкой добавленной стоимостью: Сахалинская область, Камчатский край, ЧАО, Магаданская область и РС (Якутия). Также, заметное увеличение среднедушевого товарооборота с КНР и Японией возможно при выравнивании сравнительной институциональной нагрузки для Приморского края.

В соответствии с расчетами, Амурская область и ЕАО - характеризовались наименьшим сравнительным потенциалом среднедушевого прироста торговли, поскольку основным торговым партнером данных регионов являлся Китай, а эффект границ с данной страной выступал в качестве базового показателя для оценки их сравнительного потенциала. Что касается Хабаров- 
ского края, то его можно охарактеризовать, как имеющий средний потенциал для расширения торговли со странами АТР.

Оценка сравнительного эффекта границ для каждого региона Дальнего Востока по отношению с традиционным подходом показала на некоторые расхождения по значениям торговых барьеров, которые были связаны с сокращением их разброса, а также некоторым изменением для некоторых регионов (например, РС (Якутия), по которым были осуществлены уточнения торговых потоков по сравнению с прошлым исследованием. Как и в прошлом исследовании [12], оценки которого были получены в рамках традиционного подхода, сравнительный потенциал расширения торговли регионов Дальнего Востока на душу населения главным образом может быть связан с японским рынком, а пропорционально - с американским.

Отличия между полученными оценками в рамках двух подходов заключаются в том, что при использовании современного подхода сравнительный потенциал расширения торговли дальневосточных регионов с близлежащими рынками (японским и китайским) гораздо выше, чем с территориально удаленными - США и странами ЮВА (табл. 5).

Таблий 5

Соотночение оценок увеличения торговли для регионов Дальнего Востока со странами АТР в рамках традиционного и современного подходов при выравнивании сравнительных торговых барьеров, долл.

\begin{tabular}{|l|c|c|c|c|c|}
\hline \multicolumn{1}{|c|}{ Регион } & Корея & КНР & Япония & США & Страны ЮВА \\
\hline РС (Якутия) & -11 & 37 & -22 & -15 & 9 \\
\hline Камчатский край & 0 & -38 & 106 & -19 & 54 \\
\hline Приморский край & 0 & 288 & 169 & 139 & 29 \\
\hline Хабаровский край & -54 & 35 & 16 & 117 & 0 \\
\hline Амурская область & -1 & 0 & 8 & 76 & 9 \\
\hline Магаданская область & 0 & 76 & -3 & 1381 & 135 \\
\hline Сахалинская область & 0 & -455 & -1317 & 1128 & 100 \\
\hline ЕАО & 10 & 0 & -13 & 28 & 2 \\
\hline ЧАО & 0 & -206 & 275 & 387 & 20 \\
\hline
\end{tabular}

Примечание: представлена разница между значениями, отражающими увеличение товарооборота регионов Дальнего Востока (на душу населения, долл.) при выравнивании торговых барьеров, полученными в рамках традиционного и современного подходов. Отрицательные значения означают превышение значений в рамках современного подхода над оценками, полученными в рамках традиционного подхода Источник: расчеты автора

С этой точки зрения, современный подход к оценке гравитационных зависимостей указал на то обстоятельство, что заметный потенциал для расширения торговли регионов Дальнего Востока связан, главным образом, с «естественными» торговыми партнерами - странами CВА, особенно с Японией. Данное обстоятельство подтверждает основные положения исследований торгово-экономической интеграции, которые сводятся к тому, что при либерализации внешней торговли эффект создания доминирует над эффектом отклонения в результате наращивания интенсивности взаимодействий с «ес-

7 Для периода 2002-2017 гг. в рамках традиционного подхода разница между потенциальными и текущими среднедушевыми значениями товарооборота составила: с КНР - 292 долл., с Японией - 374 долл., со странами ЮВА - 74 долл., с США - 306 долл. Подробно: [11]. 
тественными» торговыми партнерами $[18,19]$, т.е. с крупными и географически близкими рынками [20].

\section{Заключение}

Применение традиционного (на основе МНК, при исключении нулевых торговых потоков) и современного (на основе КМПП, при учете нулевых торговых потоков) подходов к оценке гравитационных зависимостей показало следующие схожие результаты: наименьшее значение эффекта границ было характерно для торговли Дальнего Востока с Кореей; с точки зрения сравнительной интенсивности торговли, наблюдался процесс сближения дальневосточной экономики с экономикой КНР; определена недостаточность выравнивания тарифной нагрузки Дальнего Востока со странами АТР для существенного роста интенсивности двусторонней торговли; по сравнительному потенциалу расширения торговых связей со странами АТР выявлены группы дальневосточных регионов со схожими характеристиками. Также, соотношение показало, что в рамках двух походов динамика значений эффекта границ, а также влияния расстояния и совместной границы имели одинаковую тенденцию.

Однако, были зафиксированы следующие принципиальные расхождения между двумя подходами. Во-первых, при одинаковом значении постоянной эластичности замещения, которое масштабирует величину эффекта границ, в рамках традиционного подхода к оценке в целом существенно занижались значения интенсивности торговли. Соответственно, полученные оценки в рамках современного подхода являлись более реалистичными, поскольку значения эффекта границ отражают определенную надбавку к цене товара. Данная надбавка не может быть слишком высокой при пересечении товара какой-либо границы. Во-вторых, в рамках современного подхода к оценке сравнительный потенциал расширения торговли регионов Дальнего Востока с близкими рынками СВА был гораздо больше, чем с удаленными США и странами ЮВА.

Таким образом, современный подход к оценке указал на заметный потенциал для расширения торговли регионов Дальнего Востока преимущественно со странами СВА, что подтверждает основные положения исследований торгово-экономической интеграции. Соответственно, двустороннему сближению, помимо смягчения волатильности различных экономических параметров, могло бы способствовать обоюдное снижение различного рода барьеров, более точная количественная оценка которых может быть получена в рамках современного подхода к расчету гравитационных уравнений.

\section{Список источников / References}

1. Atif R.M., Liu H., Haider M. Pakistan's agricultural exports, determinants and its potential: an application of stochastic frontier gravity model. The Journal of International Trade \& Economic Development, 2017, vol. 26, no. 3, pp. 257-276. DOI: 10.1080/09638199.2016.1243724

2. Anderson J.E., van Wincoop E. Gravity with gravitas: a solution to the border puzzle. American Economic Review, 2003, vol. 93, no. 1, pp. 171-192. DOI: $10.1257 / 000282803321455214$ 
3. Santos Silva J., Tenreyro S. The Log of Gravity. Review of Economics and Statistics, 2006, vol. 88, no. 4, pp. 641-658. Available at: http://www.mitpressjournals.org/doi/pdf/10.1162/rest.88.4.641 (accessed 30.08.2020)

4. Lissovolik B., Lissovolik Y. Russia and the WTO: The "Gravity" of Outsider Status. IMF European Department. WP/04/159. August 2004. Available at: https://www.imf.org/external/pubs/ft/wp/2004/wp04159.pdf (accessed 30.08.2020)

5. Van Selm G. A Gravity Model of the Former Soviet Union. Journal of International and Comparative Economics, 1995, no. 4, pp. 61-69.

6. Brock G. Russian Regional External Trading 1997-2001. Regional and Sectoral Economic Studies, 2006, vol. 6, no 1, pp. 5-20. Available at: http://www.usc.es/economet/reviews/eers611.pdf (accessed 30.08.2020)

7. Djankov S., Freund C. New Borders: Evidence from the Former Soviet Union. Weltwirtschaftliches Archiv, 2002, vol. 138, no. 3, pp. 493-508. DOI: 10.1007/BF02707951

8. Изотов Д.А., Тошков К.И. Оценка торговых барьеров Дальнего Востока России. Регионалистика, 2017, №5, cc. 61-75. [Izotov D.A., Tochkov K.I. Ocenka torgovyh bar'erov Dal'nego Vostoka Rossii [Assessment of trade barriers the Russian Far East]. Regionalistika = Regionalistics, 2017, vol. 4, no. 5, pp. 15-26.]

9. Ясеновская И.В. Межрегиональные взаимодействия субъектов Федерации в Дальневосточном районе. Хабаровск: РИЦ ХГАЭП, 2006. 124 с. [Jasenovskaja I.V. Mezhregional'nye vzaimodejstvija sub\#ektov Federacii v Dal'nevostochnom rajone [Interregional Interaction of the Subjects of Federation in the Russian Far East]. Khabarovsk: RIC HGAJeP, 2006. 124 p.]

10. Tochkov K. Trade Potential and Trade Integration of the Russian Far East: A Regional Perspective. Prostranstvennaja jekonomika = Spatial Economics, 2018, no. 4, pp. 2138. DOI: $10.14530 / \mathrm{se} .2018 .4 .021-038$

11. Изотов Д.А., Тошков К.И. Взаимодействие Дальнего Востока со странами АТР: оценка институциональных и тарифных барьеров торговли. Пространственная экономика, 2019, Том 15, №3, cc. 20-45. [Izotov D.A., Tochkov K.I. Vzaimodejstvie Dal'nego Vostoka so stranami ATR: ocenka institucional'nyh i tarifnyh bar'erov torgovli [Interaction of the Russian Far East with the Countries of the Pacific Rim: Evaluating Institutional and Tariff Trade Barriers]. Prostranstvennaja jekonomika = Spatial Economics, 2019 , vol. 15 , no. 3 , pp. 20-45. DOI: 10.14530/se.2019.3.020-045

12. Изотов Д.А., Тошков К.И. Оценка потенциала расширения торговых взаимодействий регионов Дальнего Востока со странами АТР. Регионалистика, 2019, Т.6, №5, cc. 6-30. [Izotov D.A., Tochkov K.I. Ocenka potenciala rasshirenija torgovyh vzaimodejstvij regionov Dal'nego Vostoka so stranami ATR [Trade Interactions between the Russian Far East Regions and Asia-Pacific Countries: Assessment of Potential]. Regionalistica $=$ Regionalistics, 2019, vol. 6, no. 5. pp. 6-30.]

13. Yotov Y.V., Piermartini R., Monteiro J.-A., Larch M. An Advanced Guide to Trade Policy Analysis: The Structural Gravity Model. United Nations and World Trade Organization, $2016 . \quad$ Available at: https://www.wto.org/english/res_e/booksp_e/advancedwtounctad2016_e.pdf (accessed 30.08.2020)

14. Agnosteva D., Anderson J.E., Yotov Y.V. Intra-National Trade Costs: Measures and Aggregation. National Bureau of Economic Research, NBER Working Paper No. 19872. Cambridge, MA, 2014. Available at: http://www.nber.org/papers/w19872.pdf (accessed 30.08.2020)

15. Olivero M.P., Yotov Y.V. Dynamic gravity: endogenous country size and asset accumulation. Canadian Journal of Economics, 2012, vol. 45, no. 1, pp. 64-92. DOI: 10.1111/j.1540-5982.2011.01687.x 
16. Feenstra R.C. Border Effects and the Gravity Equation: Consistent Methods for Estimation. Scottish Journal of Political Economy, 2002, vol. 49, no. 5, pp. 491-506. DOI: 10.1111/1467-9485.00244

17. A Practical Guide to Trade Policy Analysis. WTO and UNCTAD co-publication, 2012. 200 p. Available at:

https://www.wto.org/english/res_e/publications_e/wto_unctad12_e.pdf (accessed 30.08.2020)

18. Krugman P. The move toward free trade zones. Economic Review, 1991, vol. 76, pp. 525.

19. Freund C., Ornelas E. Regional Trade Agreements. Annual Review of Economics, 2010. vol. 2, pp. 139-166. DOI: 10.1146/annurev.economics.102308.124455

20. Baier S.L., Yotov Y.V., Zylkin T. On the widely differing effects of free trade agreements: Lessons from twenty years of trade integration. Journal of International Economics, 2019, vol. 116, pp. 206-226. DOI: 10.1016/j.jinteco.2018.11.002

\section{Сведения об авторе / About author}

Изотов Дмитрий Александрович, кандидат экономических наук, ведущий научный сотрудник, Институт экономических исследований ДВО РАН. 680042 Россия, г. Хабаровск, ул. Тихоокеанская, д. 153. ORCID ID: 0000-0001-9199-6226. E-mail: izotov80@yandex.ru

Dmitry A. Izotov, Candidate of Economic Sciences, Leading Researcher, Economic Research Institute of Far Eastern Branch of the Russian Academy of Sciences. 153 Tihookeanskaya Str., Khabarovsk, Russia 680042. ORCID ID: 0000-0001-9199-6226.E-mail: izotov80@yandex.ru 